\title{
Initial assessment of voltage-led demand response from UK residential loads
}

DOI:

10.1109/ISGT.2015.7131821

Link to publication record in Manchester Research Explorer

\section{Citation for published version (APA):}

Ballanti, A., \& Ochoa, L. F. (2015). Initial assessment of voltage-led demand response from UK residential loads. In IEEE/PES Innovative Smart Grid Technologies ISGT 2015 (pp. 1-5) https://doi.org/10.1109/ISGT.2015.7131821

\section{Published in:}

IEEE/PES Innovative Smart Grid Technologies ISGT 2015

\section{Citing this paper}

Please note that where the full-text provided on Manchester Research Explorer is the Author Accepted Manuscript or Proof version this may differ from the final Published version. If citing, it is advised that you check and use the publisher's definitive version.

\section{General rights}

Copyright and moral rights for the publications made accessible in the Research Explorer are retained by the authors and/or other copyright owners and it is a condition of accessing publications that users recognise and abide by the legal requirements associated with these rights.

\section{Takedown policy}

If you believe that this document breaches copyright please refer to the University of Manchester's Takedown Procedures [http://man.ac.uk/04Y6Bo] or contact uml.scholarlycommunications@manchester.ac.uk providing relevant details, so we can investigate your claim.

\section{OPEN ACCESS}




\section{Initial Assessment of Voltage-Led Demand Response from UK Residential Loads}

\author{
Andrea Ballanti \\ School of Electrical and Electronic Engineering \\ The University of Manchester \\ Manchester, UK \\ andrea.ballanti@postrgrad.manchester.ac.uk
}

\author{
Luis F. Ochoa \\ School of Electrical and Electronic Engineering \\ The University of Manchester \\ Manchester, UK \\ luis_ochoa@ieee.org
}

\begin{abstract}
One way of unlocking aggregated demand response without directly managing customers is to exploit the positive correlation between voltage and demand. This work presents an initial assessment of the potential residential response in UK primary substations (e.g., 33/11 or 33/6.6 kV) as part of the trial "Customer Load Active System Services (CLASS)" run by the distribution network operator Electricity North West Limited (ENWL). Two load modelling methodologies, time independent and time varying, are presented and applied to a single primary substation and then extended to the ENWL area. For the latter, the results considering the time-varying model, purely residential load, and $3 \%$ voltage reduction during a winter day show that it could be possible to achieve an aggregated peak reduction exceeding $150 \mathrm{MW}(>3 \%)$. Although the two load models have shown strong agreement the latter is a more accurate alternative when demand response throughout the day is of particular interest.
\end{abstract}

Index Terms-Demand response, CVR, smart grids, voltage management, exponential load model.

\section{INTRODUCTION}

Two of the major challenges for the implementation of demand response schemes, particularly by distribution network operators (DNOs), are their scalability and customer acceptance. One way of unlocking aggregated demand response of millions of residential customers without directly managing them is to exploit the positive correlation of their individual demand and voltage [1]. The latter is a parameter that can be managed directly by DNOs. However, the challenge in determining the effectiveness of this approach is to estimate the expected response of demand per voltage change throughout the day.

This work is part of the project "Customer Load Active System Services (CLASS)" run by the UK DNO Electricity North West Limited (ENWL) [2]. One of the aims of CLASS is to provide DNOs with greater understanding of voltage-led demand response. In particular, investment deferral by peak demand reduction (that decongests parts of the distribution network) and the provision of reserves to the transmission system operator (due to high penetration of renewables) are the two potential new functionalities that CLASS might unlock. These will be delivered by actions exclusively undertaken at primary substation level (i.e., 33/11 or $33 / 6.6 \mathrm{kV}$ ) using the corresponding On Load Tap Changers (OLTCs).

The concept of introducing voltage variations at the substations' OLTCs to deliver demand response is similar to that of Conservation Voltage Reduction (CVR) - an established technique mainly adopted to achieve energy savings across long periods of time. However, in CLASS it is crucial to quantify the extent to which demand responds to voltage in short periods of time (i.e., "short term" demand response [3] for peak reduction and provision of reserve) rather than its impact on daily/seasonal/yearly energy consumption (main goal of CVR). Consequently, this requires a much more granular and complex modelling of loads.

This paper presents an initial assessment of the voltagedemand relationship for the UK residential sector considering two load modeling approaches: "time-independent" and "timevarying". The former considers fix load parameters whilst the latter, by a component-based approach (i.e., bottom up) [4], is able to provide a daily demand response pattern. In both cases only residential demand during a winter peak day is considered. With these two models, an initial quantification of the potential peak reduction is assessed for a single primary substation and then extended to the ENWL area (i.e., 349 primary substations).

The paper is structured as follows: Section II introduces the methodology adopted to generate the demand profile for the considered primary substation. Section III presents the time-independent load model and in particular discusses the most suitable load parameters for the UK context. Section IV describes the time-varying methodology. In Section $\mathrm{V}$, the potential demand response for a single primary substation as well the ENWL area is estimated with both methodologies. Finally, conclusions are drawn in Section VI.

\section{DEMAND PROFILING OF A PRIMARY SUBSTATION}

This section describes the methodology adopted to produce the time-series demand profile for a single primary substation. The main characteristics of this real substation, in 


\section{Accepted Paper}

TABle I MAIN Characteristics OF STUdied PRIMARY SUbSTATION DURING PEAK DEMAND, FEBRUARY 2013

\begin{tabular}{|c|c|c|c|}
\hline $\begin{array}{c}\text { Peak demand } \\
{[\mathbf{M W}]}\end{array}$ & $\begin{array}{c}\text { Power } \\
\text { Factor }\end{array}$ & $\begin{array}{c}\text { Residential } \\
\text { Customers }\end{array}$ & $\begin{array}{c}\text { Non-residential } \\
\text { Customers }\end{array}$ \\
\hline 16.18 & 0.97 & 7968 & 357 \\
\hline
\end{tabular}

terms of load, are shown in Table I. Given that the focus in this work is to assess the potential response from residential loads, the peak demand will be considered to be entirely due to residential customers.

To model the UK residential demand the freely available tool [5], thereafter called CREST tool, has been adopted. The tool is able to stochastically generate the individual demand profile for the most common appliances found within a UK dwelling. This is a fundamental feature for the time-varying load model development as it is a bottom up approach where each type of load (i.e., appliance) is individually modelled.

The CREST tool is used to generate 7968 residential profiles considering up to date national statistics on the number of people per dwelling [6]. These profiles are then add up and scaled in order to match the actual peak value (given that substation has been assumed to be purely residential). The obtained aggregated demand profile is shown in Fig. 1.

As Fig. 1 and Table II presents the share of power demand of every appliance changes significantly within the day. Different load compositions might greatly affect the aggregated demand response as every appliance responds differently to changes in voltage [7].

Once the aggregated demand profile is obtained, it is necessary to model the corresponding voltage-demand relationship so the demand response to voltage changes can be quantified.

\section{TIME-INDEPENDENT LOAD MODEL}

To describe the input-output relationship between demand and voltage the exponential load model described in (1), [4] has been adopted. A similar equation could be written for the reactive power.

$$
P(t)=P_{0}(t)\left(\frac{V}{V_{0}}\right)^{n p}
$$

$\mathrm{P}_{0}$ is the power at the initial voltage value $\mathrm{V}_{0}$ (i.e., UK nominal single-phase, $230 \mathrm{~V}$ ) whilst $\mathrm{P}$ and $\mathrm{V}$ indicate the new variables after the voltage variations. The most important variable in (1) is the coefficient $n p$ ( $n q$ for the reactive power). Indeed, it is the parameter that defines the voltage-demand relationship. For resistance-based loads (e.g., storage space heating, kettle), $n p$ equals to 2 as a quadratic relationship exists between voltage and demand. For electronic appliances, such as TV and computers, this figure is almost zero as these loads are insensitive to voltage changes [7].

However, for an aggregated load (e.g., a primary substation) the $n p$ could, in theory, adopt any value between 0 and 2 due to the specific load composition in that instant (Fig. 1 and Table II). As a consequence, $n p$ is in reality a function of time (i.e., $n p(\mathrm{t}))$. This implies the extent to which demand
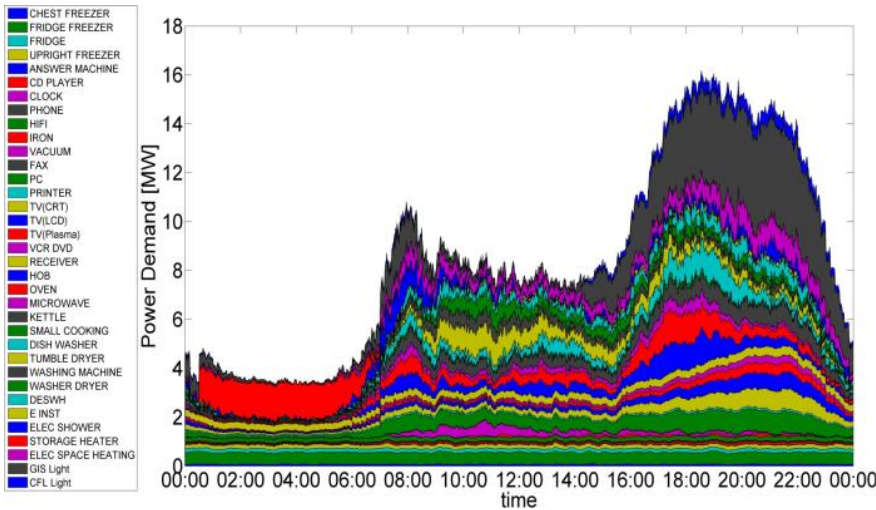

Fig. 1 Peak day aggregated demand and breakdown per appliance

TABLE II POWER SHARE PER APPLIANCE AT 02:00 AND 18:30 (PEAK)

\begin{tabular}{|c|c|c|c|c|c|c|c|}
\hline Instant & Heating & Light & Wet & ICT & Cook & Cold & Others \\
\hline $02: 00$ & $40 \%$ & $5 \%$ & $1 \%$ & $25 \%$ & $\sim 5 \%$ & $24 \%$ & $\sim 0 \%$ \\
\hline $18: 30$ & $12 \%$ & $26 \%$ & $13 \%$ & $20 \%$ & $23 \%$ & $5 \%$ & $1 \%$ \\
\hline
\end{tabular}

TABLE III LITERATURE REVIEW MAIN OUTCOMES ON AGGREGATE RESIDENTIAL LOAD MODEL FOR WINTER PERIOD

\begin{tabular}{|c|c|c|c|}
\hline Ref -Year-Country & $\boldsymbol{n p}$ & $\boldsymbol{n q}$ & $\boldsymbol{\Delta} \mathbf{V}_{\max }$ \\
\hline$[8]-2014-N e t h$. & 1.50 & NA & $+3 /-6 \%$ \\
\hline$[9]-2013-U S A$ & 1.24 & NA & $-4 \%$ \\
\hline$[10]-2008-S e r b i a$ & 1.40 & 3.5 & $+10 /-5 \%$ \\
\hline$[11]-2007-U S A$ & $0.50-1.10$ & NA & $-4 \%$ \\
\hline$[12]-2006-$ Argentina & 1.10 & 4.5 & $\pm 4 \%$ \\
\hline \multicolumn{4}{|l}{}
\end{tabular}

responds to changes in voltage during short period of times (i.e., minutes) varies throughout the day. Although the determination of this behavior represents a real challenge, as the effective load composition is not known, it is fundamental to determine the benefits in different services such as peak reduction or provision of reserves. However, most of the available literature defines the voltage-demand relationship adopting only seasonal [9], [12] if not yearly load models [13] (i.e., $n p=$ constant within a day). This section adopts the same approximation by introducing the time-independent load model.

There are a number of international studies that quantify the aggregated voltage-demand response at a primary (or secondary) substation level. To select the most adequate ones, first a higher priority has been given to recent studies where the voltage-demand relationship for winter (when possible) residential load is based and/or validated by field measurements. Availability of the performed voltage variation $\left(\Delta \mathrm{V}_{\max }=\mathrm{V}-\mathrm{V}_{0}\right)$ at the substation level without affecting customers downstream is also considered. Following these criteria, the most relevant studies and their outcomes, i.e., $n p$, $n q$ and $\Delta \mathrm{V}_{\max }$, are shown in Table III.

\section{A. Defining $n p$}

As it can be seen in Table III, no strong agreement exists among these studies. Different load composition, location, climate, and also measurement methodologies might affect significantly the load modelling outcomes. Consequently, none of the previous load models can be considered reliable for the specific UK residential demand without previous analysis. 


\section{Accepted Paper}

In [8] the $n p$ factor of 1.5 estimates the so called "transient" characteristic rather than the steady-state (that tends to be lower [10]) which is essential for peak demand reduction and the provision of reserves. In [10] the steadystate $n p$ factor of 1.4 represents an overestimation of the demand response for the UK residential sector where water and space heating appliances are mainly supplied by gas. In [11] a $n p$ coefficient from 0.5 to 1.1 is likely to be affected by the significant use of air conditioning systems (common in USA), characterized by a low demand response ( $n p=0.3$, [14]). Hence, a slightly higher $n p$ would be expected for UK residential customers.

From the above discussion, $n p$ parameters between 1 and 1.3 are more realistic for the UK residential context. Although any value within this range could be investigated, in this work an $n p$ equal to 1.1 is chosen. This conservative figure is consistent with [9],[15] and [12].

\section{B. Defining $n q$ and $\Delta V_{\max }$}

The lack of in-depth studies on reactive power demand response makes it difficult to find an initial robust estimation for the $n q$ factor. As a consequence a value of 3.5 is the adopted to model the winter UK residential demand [10].

An allowable voltage variation, $\Delta \mathrm{V}_{\max }$, of $3 \%$ at the primary substation level (i.e., two tap steps for the typical OLTC within ENWL) has been chosen. This is aligned with most of the above studies.

\section{Summary}

Table IV summarizes the adopted values to model the winter UK residential load demand in the "time-independent" load model.

A number of caveats need to be noted:

1. $n p$ and $n q$ are constant throughout the day whilst in reality the power response to a voltage variation will change due to the changes in load composition;

2. The adopted $n p$ and $n q$ values are based on literature (mainly from USA). No measurement-based studies has been found for the UK;

3. Only residential demand has been considered;

4. The effects of the adopted $\Delta \mathrm{V}_{\max }$ on end customers have not been validated in UK networks.

Although the adopted parameters for the time-independent model should be taken with caution, they represent an ideal starting point to assess the potential peak reduction capabilities that the voltage-led residential demand response in the UK might unlock.

\section{TIME-VARYING LOAD MODEL}

This section investigates a more sophisticated technique to model the voltage dependency of the residential demand. In particular, a component-based approach [4] will be developed in order to introduce a "time-varying" load model. In Fig. 2 the adopted procedure is illustrated.

First, a literature review has been carried out in order to generate a database containing the ZIP load model (2) (as

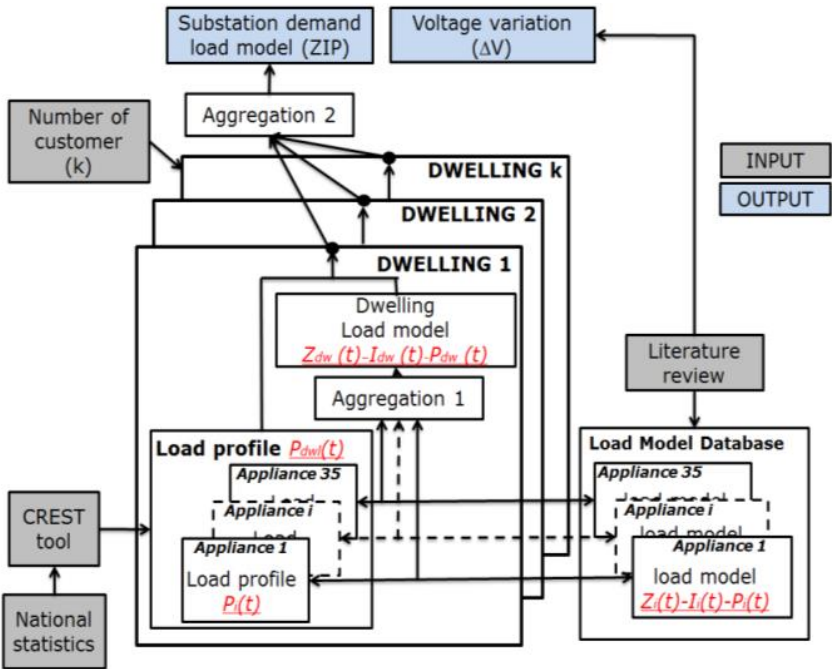

Fig. 2 Time-varying load model procedure

TABLE IV TIME-INDEPENDENT LOAD MODEL COEFFICIENTS AND

\begin{tabular}{|c|c|c|c|}
\cline { 2 - 4 } \multicolumn{1}{c|}{} & \multicolumn{4}{c}{ ALLOWABLE VOLTAGE VARIATION } \\
\cline { 2 - 4 } \multicolumn{1}{c|}{} & $\boldsymbol{n}$ & $\boldsymbol{n q}$ & $\Delta \mathbf{V}_{\max }$ \\
\hline Winter & 1.1 & 3.5 & $\pm 3 \%$ \\
\hline
\end{tabular}

more precise than the exponential [4]) of each single $i$-th appliance [14], [7]. Thereafter, the ZIP parameters of each appliance (a total of 35 appliances in Fig. 2), in agreement with their demand profile (i.e., $P_{i}(t)$ known from the CREST tool), are aggregated. One set of ZIP parameters (i.e., $Z_{d w}, I_{d w}$ and $P_{d w}$ in Fig. 2) for the whole dwelling is obtained adopting the formulation in [16] ("Aggregation 1" in Fig. 2).

Following this a second aggregation process ("Aggregation 2" in Fig. 2), formally identical to the previous, provides one set of ZIP parameters for the whole primary substation stacking up each of the dwelling profiles [16]. For the time-varying load model the same allowable voltage variation found in the literature (i.e., $\Delta \mathrm{V}_{\max }=3 \%$ ) has been adopted. In Fig. 3, the obtained load model is shown and the equivalent $n p$ and $n q$ are used for visualization purposes. The most important findings is the that the $n p$ and $n q$ parameters are now functions of time $(n p(t), n q(t))$. Indeed, the simulated load composition minute by minute (Fig. 1) is considered.

$$
P_{i}(t)=P_{0}(t)\left[Z_{i}(t)\left(\frac{V}{V_{0}}\right)^{2}+I_{i}(t)\left(\frac{V}{V_{0}}\right)+P_{i}(t)\right]
$$

Fig. 3 describes a more realistic behavior of the load consistent with other similar studies where the measured $n p(t)$ oscillates from 0.8 to 1.2 during a winter day [3].

In Fig. 3, for the time-independent load model the fixed $n p$ factor of 1.1 (green line), can be considered reliable during night hours but an underestimation for the rest of the day. Moreover, it should be highlighted that different load compositions (e.g., less or more space heating appliances) can change significantly the response during the night, making the time-independent model less reliable also within this period as compared to the time-varying one. 


\section{Accepted Paper}
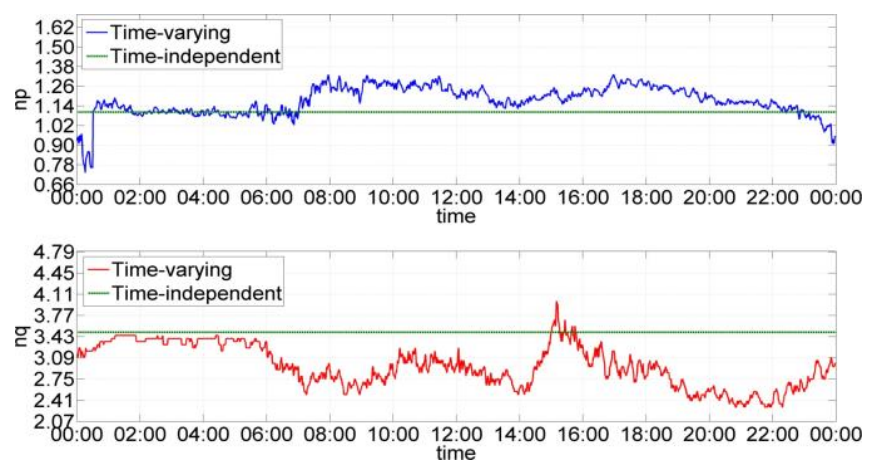

Fig. $3 n p$ and $n q$ factor for the peak day for the analysed primary substation

\section{DEMAND RESPONSE ASSESSMENT}

\section{A. Primary Substation: daily demand response}

Once the demand profile $\left(\mathrm{P}_{0}(\mathrm{t})\right.$, Fig. 1), load parameters ( $n p, n q$ in Table IV and Fig. 3) and voltage variation $\left(\Delta \mathrm{V}_{\max }=3 \%\right)$ had been determined for both methodologies, the demand response at the primary substation level could be assessed (1). The results, expressed in term of absolute power variation $\left(\Delta \mathrm{P}(\mathrm{t})=\mathrm{P}_{0}(\mathrm{t})-\mathrm{P}(\mathrm{t})\right)$ are shown in Fig. 4. Results for the specific peak time (18:30) are summarized in Table $\mathrm{V}$. It is worth highlighting that, due to the nature of the adopted models, the demand response shown in Fig. 4 represents both load increases and decreases (assuming a $\Delta \mathrm{V}_{\max }= \pm 3 \%$ ).

The daily variations in demand shown by the timeindependent load model (green lines) are only due to the natural variations in demand (from 4 to $16.18 \mathrm{MW}$ as shown in Fig. 1) as the actual load composition is not considered. On the other hand, higher daily variations could be noticed in Fig. 4 for the time-varying load model as a consequence of both the variations in demand and the load parameters variations through the day (blue line). This is an expected and realistic behavior [3] that increases the reliability in the obtained results allowing a more precise estimation of demand responsiveness throughout the day.

In terms of peak reduction, 0.6 and $0.51 \mathrm{MW}$ (i.e., 3.7 and $3.3 \%$ ) were estimated with the time-varying and timeindependent load models, respectively (Table V). This is the highest difference found between them (about 13\%). It is at this very moment that the highest possible accuracy is needed to estimate the benefits to be unlocked by the voltage-led demand response. Nonetheless, considering a demand growth of 1 to $2 \%$ per annum (typical for the UK), the reduction estimated by both models could mean a potential investment deferral of up to 3-4 years for similar primary substations.

At night only around 0.1 MW of response is estimated for both models. However, other primary substations with different penetration of space heating appliances are likely to show different demand response capabilities at night that cannot be captured by the time-independent model.

The proposed time-varying model demonstrates that, due to the changes in residential load composition throughout the day, the potential demand response also varies. This behavior is not captured by the time-independent load model and all

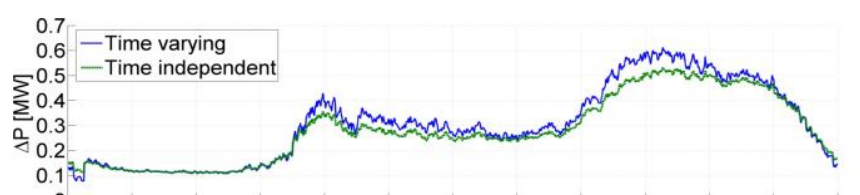

08:00 02:00 04:00 06:00 08:00 10:00 $\begin{gathered}12: 00 \\ \text { time }\end{gathered}$ 14:00 16:00 18:00 20:00 22:00 00:00

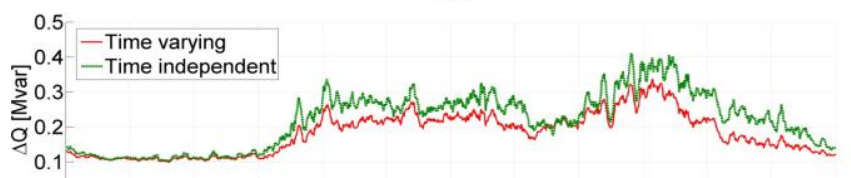

08:00 02:00 04:00 06:00 08:00 10:00 12:00 14:00 16:00 18:00 20:00 22:00 00:00 Fig. 4 Potential demand response at peak for the analysed primary substation $\left(\Delta \mathrm{V}_{\mathrm{MAX}}= \pm 3 \%\right)$

TABLE V TIME-VARYING AND TIME-INDEPENDENT MAIN RESULTS AT PEAK $\left(\Delta \mathrm{V}_{\mathrm{MAX}}=-3 \%\right)$ FOR THE ANALYSED PRIMARY SUBSTATION

\begin{tabular}{|c|c|c|c|c|c|c|}
\hline & $\begin{array}{c}\mathbf{P} \\
{[\mathbf{M W}]}\end{array}$ & $\boldsymbol{n p}$ & $\begin{array}{c}\Delta \mathbf{P}[\mathbf{M W}] \\
(\boldsymbol{\%})\end{array}$ & $\begin{array}{c}\mathbf{Q} \\
{[\mathbf{M v a r}]}\end{array}$ & $\boldsymbol{n q}$ & $\begin{array}{c}\Delta \mathbf{Q}[\mathbf{M v a r}] \\
(\boldsymbol{\%})\end{array}$ \\
\hline T. ind. & 16.18 & 1.10 & $0.51-(3.3)$ & 4.06 & 3.5 & $0.41-(10.1)$ \\
\hline T. var. & 16.18 & 1.24 & $0.60-(3.7)$ & 4.06 & 2.9 & $0.31-(7.6)$ \\
\hline
\end{tabular}

other studies where this approach is adopted [13], [9]. Consequently, it is crucial that any future analysis considers this more advanced modelling.

Based on the above, the time-varying load model, in combination with validated parameters (via trials such as the CLASS project), can potentially allow DNOs to confidently determine volumes of demand response available for different services at any moment in time.

\section{B. ENWL Area: Peak Reduction}

This section aims to introduce the first assessment on the potential peak reduction of the ENWL area. For this purpose, the findings obtained in Fig. 3 and summarized in Table V (i.e., $n p=1.1$ and $n p=1.24$ ) are extended to the peak demand of 349 primary substations. Adopting (1) (where $\mathrm{P}_{0}(\mathrm{t})$ is the primary substation peak demand), the corresponding results are presented in Fig. 5 and Table VI.

From Fig. 5 about $37 \%$ of primary substations could achieve a peak reduction between 0.35 and $0.50 \mathrm{MW}$ considering the time-independent load model. As expected, higher peak reductions (blue bars) were estimated by the time-varying model due to its higher $n p$. In the aggregate, a total of $143.74 \mathrm{MW}$ is estimated by the time-independent model. The time-varying estimates almost $20 \mathrm{MW}$ more (i.e., 161.67 MW), with an average of $0.46 \mathrm{MW}$ per substation (dashed lines).

It is important to highlight that the peak demand for the ENWL area have been considered to be entirely domestic and all substations assumed to peak at the same time. Moreover, no network study has been carried out to determine the effective $\Delta \mathrm{V}_{\max }$. As a consequence, although these estimations could be considered as an upper limit, they provide a preliminary assessment of the demand response capability in terms of peak reduction. In addition, although only around $1 / 15$ of the total UK demand has been considered, the estimated volume is three times higher than 


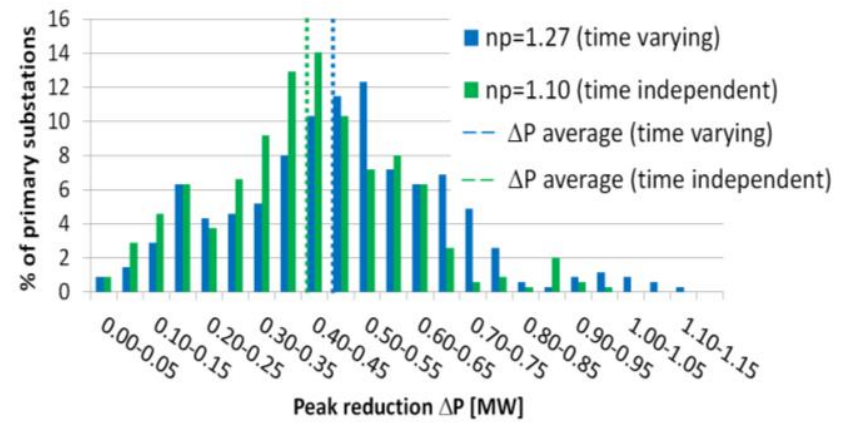

Fig. 5 Distribution of absolute peak reduction with both load models assuming $\Delta \mathrm{V}_{\max }=-3 \%$ per primary substations in the ENWL area

Table VI Time-Varying and Time-IndePendent main Results at PeaK $\left(\Delta \mathrm{V}_{\mathrm{MAX}}=-3 \%\right)$ FOR THE ENWL AREA

\begin{tabular}{|l|c|c|c|c|}
\hline & $\mathbf{P}[\mathbf{M W}]$ & $\boldsymbol{n} \boldsymbol{p}$ & $\Delta \mathbf{P}[\mathbf{M W}]-(\boldsymbol{\%})$ & $\Delta \mathbf{P}[\mathbf{M W}]$ per sub. \\
\hline T. ind. & 4362 & 1.10 & $143.74-(3.3)$ & 0.46 \\
\hline T. var. & 4362 & 1.24 & $161.67-(3.7)$ & 0.41 \\
\hline
\end{tabular}

the minimum capability of $50 \mathrm{MW}$ currently requested by the transmission system operator to provide fast reserves.

\section{CONCLUSIONS}

This paper has discussed the modelling aspects and initial findings of aggregated UK residential demand response to changes in voltage for a winter day. In particular, two different load modelling approaches were introduced: "timeindependent" and "time-varying". The former applies fixed load parameters whilst the latter has considered a likely load composition of the demand through a component-based approach.

Both methodologies were applied to a real primary substation. The time-varying load model was capable of providing a daily pattern for the load parameters (i.e., $n p(t)$ and $n q(t))$ in agreement with the expected, natural load composition variations. The main advantage of the timevarying methodology is that allows a more accurate estimation of the aggregated load model based on the likely composition of appliances used throughout the day. This is key for the provision of services as it increases the confidence in the volumes of demand response that can be offered throughout the day. In addition, its flexibility and capacity to be generalized to other substations, if information on load composition is made available, is another potential advantage that allows applying the methodology to other substations.

The application of the time-varying load model to 349 primary substations, assumed to be purely residential and considering $3 \%$ voltage reduction during a winter day, showed that it could be possible to achieve an aggregated peak reduction exceeding $150 \mathrm{MW}$ (>3\%). This volume of demand response, derived from an area accounting for around 1/15 of the UK peak demand, is above the minimum requested by the transmission system operator to provide fast reserves.

Future measurements from the CLASS trials will allow improving/validating the time-varying load model. In addition, network studies will estimate the effective voltage variation that could in reality be applied without affecting customers.

\section{ACKNOWELDGMENTS}

The authors would like to thank Electricity North West Limited (ENWL), UK for the data adopted in this paper and also the Centre for Renewable, UK, for making available the CREST tool.

\section{REFERENCES}

[1] M. S. Chen, R. Shoults, J. Fitzer, and H. Songster, "The Effects of Reduced Voltages on the Efficiency of Electric Loads," Power Apparatus and Systems, IEEE Transactions on, vol. PAS-101, pp. 2158-2166, 1982.

[2] (2014). Customer Load Active System Services. Available: http://www.enwl.co.uk/class

[3] Z. Wang and J. Wang, "Time-Varying Stochastic Assessment of Conservation Voltage Reduction Based on Load Modeling," Power Systems, IEEE Transactions on, vol. PP, pp. 1-8, 2014.

[4] C. W. C4.605, "Modelling and aggregation of loads in flexible power networks," 2014.

[5] I. Richardson and M. Thomson, "Domestic electricity demand model simulation example," ed, 2010.

[6] "Families and household 2013," Office for National Statistics2013.

[7] A. Bokhari, A. Alkan, R. Dogan, M. Diaz-Aguilo, F. de Leon, D. Czarkowski, et al., "Experimental Determination of the ZIP Coefficients for Modern Residential, Commercial, and Industrial Loads," Power Delivery, IEEE Transactions on, vol. PP, pp. 1-1, 2013.

[8] P. Kadurek, J. F. G. Cobben, W. L. Kling, and P. F. Ribeiro, "Aiding Power System Support by Means of Voltage Control With Intelligent Distribution Substation," Smart Grid, IEEE Transactions on, vol. 5, pp. 84-91, 2014.

[9] "EPRI Smart grid demonstration initiative 5 Year update," 2013.

[10] L. M. Korunovic, D. P. Stojanovic, and J. V. Milanovic, "Identification of static load characteristics based on measurements in medium-voltage distribution network," Generation, Transmission \& Distribution, IET, vol. 2, pp. 227-234, 2008.

[11] N. e. e. alliance, "Distribution efficiency initiative," 2007.

[12] J. L. Aguero, M. B. Barbieri, and M. C. Beroqui, "Voltage depending load models. Validation by voltage step tests," in Power Engineering Society General Meeting, 2006. IEEE, 2006, p. 6 pp.

[13] P. Kadurek, M. M. Sarab, J. F. G. Cobben, and W. L. Kling, "Assessment of demand response possibilities by means of voltage control with intelligent MV/LV distribution substation," in Power and Energy Society General Meeting, 2012 IEEE, 2012, pp. 1-6.

[14] C. Cresswell, "Steady State Load Models for Power System Analysis," Doctor of Philosophy, School of electrical and electronic engineering, The University of Edinburgh, 2009.

[15] G. Tsagarakis, A. J. Collin, A. E. Kiprakis, and S. McLaughlin, "Voltage control of UK residential customers for power reduction," in PowerTech (POWERTECH), 2013 IEEE Grenoble, 2013, pp. 1-6.

[16] F. Lamberti, D. Cuicai, V. Calderaro, and L. F. Ochoa, "Estimating the load response to voltage changes at UK primary substations," in Innovative Smart Grid Technologies Europe (ISGT EUROPE), 2013 4th IEEE/PES, 2013, pp. 1-5. 